Afrika Focus, Vol.8, Nr.1, 1992,pp 33-47

\title{
DE ERFENIS VAN MOBUTU
}

\section{Geert VERGAERDE}

Heirweg 30

8431 Middelkerke

ONDERZOEKSVELD: politiek in Afrika

\section{SUMMARY}

\section{THE LEGACY OF MOBUTU}

This article intends to give an explanation of the possible consequences for Zaire of 25 years of Mobutist regime. This is important, because during the second republic there was a constant growth of a regime sui generis with fundamental characteristics that, in the near future, will have an important influence on the political, social and economic events.

- The division of the enormous amount of power could result in heavy quarrels.

- For years, there has not been an independent political elite, so that the formation of such an elite in a short period of time will be very difficult.

- The patrimonialistic style of government has resulted in a political environment that is composed of informal networks and dependent relations, with in the centre Mobutu.

- The continuing cycle of opposition and collaboration has brought severe damage to the image and credibility of the opposition. Besides, there is a big gap between the political elite and the population. 
- The policy of ethnic mobilisation has increased the ethnic consciousness.

- Patrimonialism and parasitism have generated a pandemic corruption in all layers of the population.

- The policy of borrowing money has led to gigantic debts and the loans have not led to any development of the economic capacity.

- The insecure position of the political and economic executives has created a spiral of insecurity and corruption, which, on its turn, has created an dialectic of repression.

KEY WORDS: Mobutu, Political reforms, Zaire

\section{Inleiding}

Sinds de politieke situatie in Zaïre na de beloften tot hervormingen en democratie, in een labiele toestand is terechtgekomen, lijkt de bevolking en een op zijn minst belangrijk deel van de politieke top zich te willen ontdoen van het verleden. President Mobutu, meer dan wie ook de verpersoonlijking van de recente geschiedenis van Zaire, heeft dan ook bij de grote oppositiepartijen en de bevolking alle krediet verloren. Maar het regime sui generis, dat Mobutu ingericht heeft met als doel zijn macht te behouden en te vergroten, heeft enkele eigenschappen en uitwassen, waarmee Zaïre niet alleen gedurende de tweede republiek geconfronteerd werd, maar die ook in de toekomst meer dan waarschijnlijk hun invloed zullen laten gelden.

\section{Gevolgen van de persoonlijke regeerstijl van Mobutu}

Door de politieke chaos en de voortdurende onzekerheid van de eerste republiek ontstond er een gevoel van paranoia bij de meeste leidinggevende personen. Onder andere dit gevoel heeft de president er toe aangezet de staat en al de functies ervan op zijn persoonlijkheid en zijn wil af te stemmen. Dwangmacht, sanctiemacht, controle over de schaarse middelen, informatiemacht, psychologische macht, formele macht, enz..., waren geconcentreerd in de handen van én persoon. Het voorstel van sommigen om de grondwet te vervangen door én artikel, nl.:"le 
pouvoir est exercé par le président de la république" (1), mag dan schertsend geformuleerd geweest zijn, het was dan toch een cynische samenvatting van de realiteit. Het voor de hand liggende gevaar nu van een eventuele opsplitsing van deze geweldige machtsconcentratie is een machtsstrijd tussen de politieke erfgenamen van het oude regime. Het uiteenrafelen van het met de jaren gegroeide organisch geheel zal ongetwijfeld velen water en bloed doen zweten en zal misschien aanleiding geven tot meer centrifugale tendensen (zie ook punt 4) dan de meesten lief is.

Hieruit voortredenerend kunnen we ons ook de vraag stellen of er überhaupt wel iemand is die bereid én bekwaam is om de verantwoordelijkheid op zich te nemen. Het monocephalisme, zo typerend voor de tweede republiek, stond immers niet toe dat iemand zich in de schaduw van Mobutu zou opwerken tot een potentiële rivaal of opvolger. In de beginjaren van de republiek werd dit duidelijk gemaakt door de politieke uitschakeling van het leger als belangrijke machtsfactor en van de Binzagroep (met figuren zoals Nendaka, Bomboko, Ndele, Adoula) of de fysieke uitschakeling van Tshombé en Mulele (of later de officieren Tshibangu en Ikuku, die zich gedurende de Shaba-crisis bijzonder populair hadden gemaakt door hun waakzaamheid en heldhaftigheid) (2). Later werd trouw aan en afhankelijkheid van het staatshoofd het belangrijkste criterium voor het verwerven van een belangrijke positie. Geleidelijk werden alle topniveaus ingenomen door de cadres die geen serieuze bedreiging voor de macht meer vormden (3).

We willen dus de doenbaarheid betwijfelen van de (wensbare) oprichting van een onafhankelijke politieke elite op korte termijn, in een land waar decennia lang het tegengestelde betracht en gerealiseerd werd. Het volledige gebrek aan verantwoordelijkheid en het hiermee gepaard gaande gebrek aan ervaring zullen in de toekomst beslist een hoge tol eisen.

Bovendien valt het ook nog te betwijfelen of het patrimonialisme, waarbij het regeren wordt gezien als het privé-domein van de leider en de autoriteit voortvloeit uit de persoonlijkheid van de leider, wel toelaat dat de bestaande organisatie van de Zaïrese staat overgenomen wordt door andere figuren (4). Kenmerkend voor het patrimonialisme (5) is immers onder andere hẹt zich toeëigenen van openbare functies, waardoor op alle hoge posten vertrouwelingen worden geparachuteerd. Een tweede kenmerk is het privatiseren van politieke relaties. De machtsstructuur wordt gekenmerkt door informele netwerken en persoonlijke afhankelijkheidsrelaties, waarbij medewerkers niet zozeer officiële ambtenaren zijn, maar kameraden die persoonlijk aan de chef gebonden zijn. Tenslotte is er ook nog de persoonlijke loyaliteit die doorweegt boven de dienstbaarheid aan het algemeen belang (bv. de Division spéciale présidentielle). Het patrimonialistisch type van 


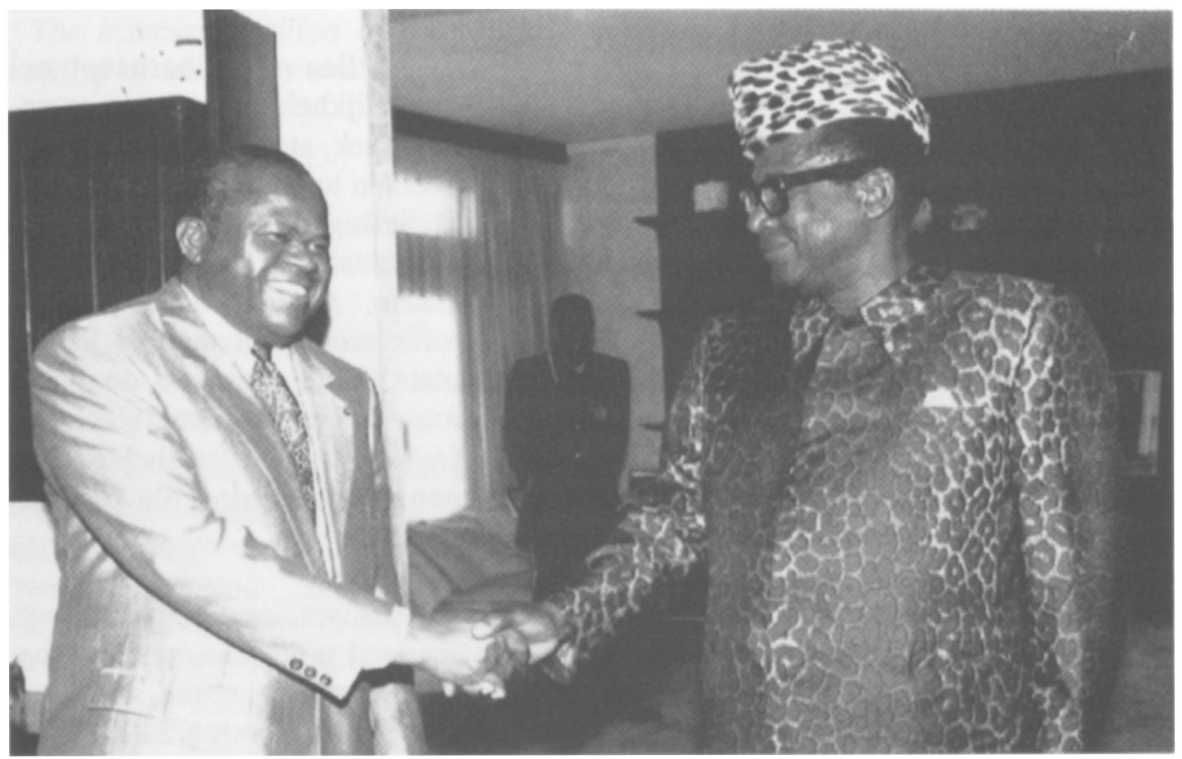

30 september 1991, President Mobutu schudt uiteindelijk de hand met Etienne Tshisekedi, die toen pas aangewezen was als eerste minister

Archief Het Volk 0 
bestuur, waarmee Mobutu Zaïre doordrenkt heeft, is dermate gebaseerd op persoonlijke en informele relaties, dat we ons kunnen afvragen of het behoud van het Zaïrees bestuurlijk apparaat wel doenbaar is eens zijn founding father van het toneel verdwenen is. Ook op dit vlak is het dus mogelijk dat het Zaïre van de toekomst moeilijkheden zal kennen, en dit door de eventuele noodzaak om een gans systeem af te breken en weer van de grond af op te bouwen. Het alternatief lijkt al evenmin erg hoopgevend: het voortbestaan van een bureaucratie die zich voornamelijk laat leiden door informele regels en contacten, die niet kunnen worden tenietgedaan door wetgeving.

Verder mogen we niet uit het oog verliezen dat president Mobutu zelf nog over enkele troeven beschikt, hoewel we hier wel dienen op te passen de grenzen van het speculatieve niet te overschrijden. Hij had tot nu nog altijd het initiatief in handen met betrekking tot de aan de hand zijnde hervormingen. De consultations, de nieuwe grondwet, het multipartisme werden slechts doorgevoerd na zijn goedkeuring, die nog altijd cruciaal lijkt te zijn. De herrie rond de samenstelling van de conférence nationale toont dit ook aan: wordt er iets ondernomen dat niet naar de zin van de president is, dan kan men gegarandeerd rekenen op eindeloze vertragingsmaneuvers en bureaucratische sabotage. Een andere troef is zijn nog steeds zeer grote persoonlijke rijkdom, waarmee hij zijn afhankelijkheidsrelaties nog een tijd in stand kan houden. Ten derde teert de president nog altijd op zijn reputatie van vredestichter. $\mathrm{Na}$ de chaotische en bloedige jaren van de eerste republiek was iedereen hem zeer dankbaar omwille van het feit dat hij Zaïre verlost had van dergelijke calamiteiten, die van een zodanige omvang waren dat ze nu nog levendig voortleven in de herinneringen van de Zaïrezen. Het lijkt niet ondenkbaar dat indien Zaïre steeds verder afglijdt naar de chaos, hij zich op het juiste moment als een Deus ex machina zal presenteren, om het verdeelde volk weer onder zijn leiderschap te verenigen.

Tenslotte is er ook nog zijn grote bedrevenheid in het manipuleren van politieke tegenstanders en medestanders. Gebruikmakend van een zeer goede kennis van de wekelijke motieven en zwaktes van zijn tegenstanders (zie ook punt 3), slaagt hij er nog steeds in bepaalde personen rond zich te scharen en verdeeldheid te zaaien bij zijn tegenstanders. Dit werd recent nog prachtig geillustreerd met de (zoveelste) benoeming van Nguza Karl I Bond tot premier. Hiermee werd een van zijn belangrijkste rivalen uitgeschakeld en werd het voorheen zo solide lijkende heilig verbond een rake klap toegediend, maar bovendien werd aangetoond dat Mobutu zeker nog niet machteloos is.

Tot besluit kunnen we dus stellen dat Mobutu als machtsfactor (voorlopig) nog niet afgeschreven blijkt en dit op grond van zijn reputatie, zijn cliëntelistische 
netwerken, de staatsstructuur die op zijn maat gesneden is en wegens de zwakte van de alternatieven.

\section{De zwakte van de oppositie}

Jarenlang is er in het Zaïrese politieke milieu geen serieuze oppositie geweest. Ook dit vloeit voort uit een essentieel kenmerk van Mobutu's regeerstijl. Immers, om elke potentiële opposant de pas af te snijden, gedroeg hij zich tegenover de politici als een pater familias die hen allen opnam in de grote MPR-familie, waar aan al hun wensen werd tegemoetgekomen. Wanneer ze zich echter niet behoorlijk gedroegen, werden ze regelmatig op de vingers getikt en gestraft, waarna ze echter steevast met veel liefde weer in de familie werden opgenomen. Een dergelijke manipulatie was mogelijk doordat figuren zoals Tshisekedi, Nguza en anderen in feite geen ommekeer in het bestel wensten, maar een meer autonome positie binnen de toplaag (6), waardoor ze zeer gevoelig bleken te zijn voor de verlokkingen van de macht. De voortdurende cyclus van ballingschap - amnestie - deelname aan de macht, waarmee bv. Nguza nogal wat ervaring had, doet ons vragen stellen naar de geloofwaardigheid en oprechtheid van de huidige politici, die zowat allen op de een of andere manier hebben deelgenomen aan het Mobutistisch bewind.

Een van de gevolgen is dan ook dat we dienen te twijfelen aan daadwerkelijke steun vanwege het volk voor alternatieven die vandaag de dag naar voor worden geschoven. Politieke oppositie stricto sensu is er trouwens nooit echt geweest onder de bevolking. Het betrof veeleer een vlucht voor het regime en zijn alomvattende macht, in de informele sector, de religie en het zich organiseren op kleine schaal tegen de misbruiken van de overheid. Het objectieve bondgenootschap dat nu is ontstaan tussen de bevolking en de oppositie, berust allicht niet op warme genegenheid, daar de doelstellingen ver uit elkaar liggen (maar elkaar niet noodzakelijk tegenspreken). Bovendien rekenen de oppositieleden niet echt op de bevolking om hen aan de macht te brengen. Ze wensen niet echt dat er een eigen actie van het volk komt, daar ze riskeren hun plaats er niet in te vinden (7).

We kunnen dus concluderen dat het in de lijn der verwachtingen zal liggen dat de oppositie haar doelstellingen zal beperken tot het veroveren van de macht en niet zodanig tot het verbeteren van de leefomstandigheden van het volk, waarmee weinig voeling bestaat. Dit wil echter niet zeggen dat de bevolking op een gelijkaardige manier zal behandeld worden als gedurende de tweede republiek, maar wel dat hun verzuchtingen waarschijnlijk niet bovenaan de prioriteitenlijst zullen staan. 


\section{Het bestaan van een politieke aristocratie}

Zoals hierboven reeds is aangegeven, is de feitelijke macht in Zaïre in handen van een elite die met de top verbonden is via patroon-cliënt relaties. Immers, na de jaren ' 60 werd de zwaar verdeelde politieke en economische top onder én dak gebracht, nl. de MPR. In de daaropvolgende jaren werd het behoud of het verwerven van een economische toppositie (gedurende de zaïrisation) (8) of van een politieke toppositie afhankelijk gesteld van de trouw aan het regime. Eens die positie veroverd, kon men zonder veel problemen uitgebreid parasiteren. Hoe meer er van dit systeem gebruik werd gemaakt, hoe tevredener de president was. Immers, ten eerste ontstond er een klasse van Kings's men, die door de creatie van inkomens in een afhankelijkheidsrelatie geduwd werden. Ten tweede waren de voordelen van een plaats in de elite zo groot dat men alle aandacht ging verliezen voor beleids- of ideologische kwesties en men zich volledig ging toeleggen op het verwerven van een positie in het systeem. En ten derde werd zodoende de opkomst vermeden van een klasse van ondernemers die hun rijkdom te danken hadden aan factoren die niet binnen de invloedssfeer van de president lagen (9). Zodoende werd het behoud van de macht niet bedreigd door alternatieve machtsbases. Bijgevolg zit Zaïre nu opgescheept met een elite wiens hoofdbezigheid parasiteren is en die elke creatieve economische activiteit verstikt. Bovendien bestaat het gevaar dat, indien in de toekomst de president als unificerende factor wegvalt, de etnische tegenstellingen het land verscheuren.

We kunnen stellen dat Mobutu de afgelopen jaren een wafelijzerpolitiek à la Zaïre toegepast heeft. Door een handig en subtiel bespelen van de heersende rivaliteiten zorgde hij ervoor dat Kinshasa voor alles het centrum bleef en de rest van het land verdeeld was. De belangrijkste krachten van de verschillende groepen bond hij aan zich door hun baronnen tot vertegenwoordigers van het regime te verheffen. Daarbij werden de felbegeerde benoemingen die toegang gaven tot het beheer van de staat, geregeld volgens een etnische verdeelsleutel (10). Etniciteit werd dus gebruikt om macht te mobiliseren, waardoor het katalyserend werkte op het etnisch bewustzijn.

Besluitend kunnen we stellen dat Mobutu in het centrum stond van cliëntelistische en etnische relaties en dat bijgevolg het opdoeken van deze netwerken een taak zal zijn waarbij men uiterst voorzichtig zal moeten te werk gaan. 


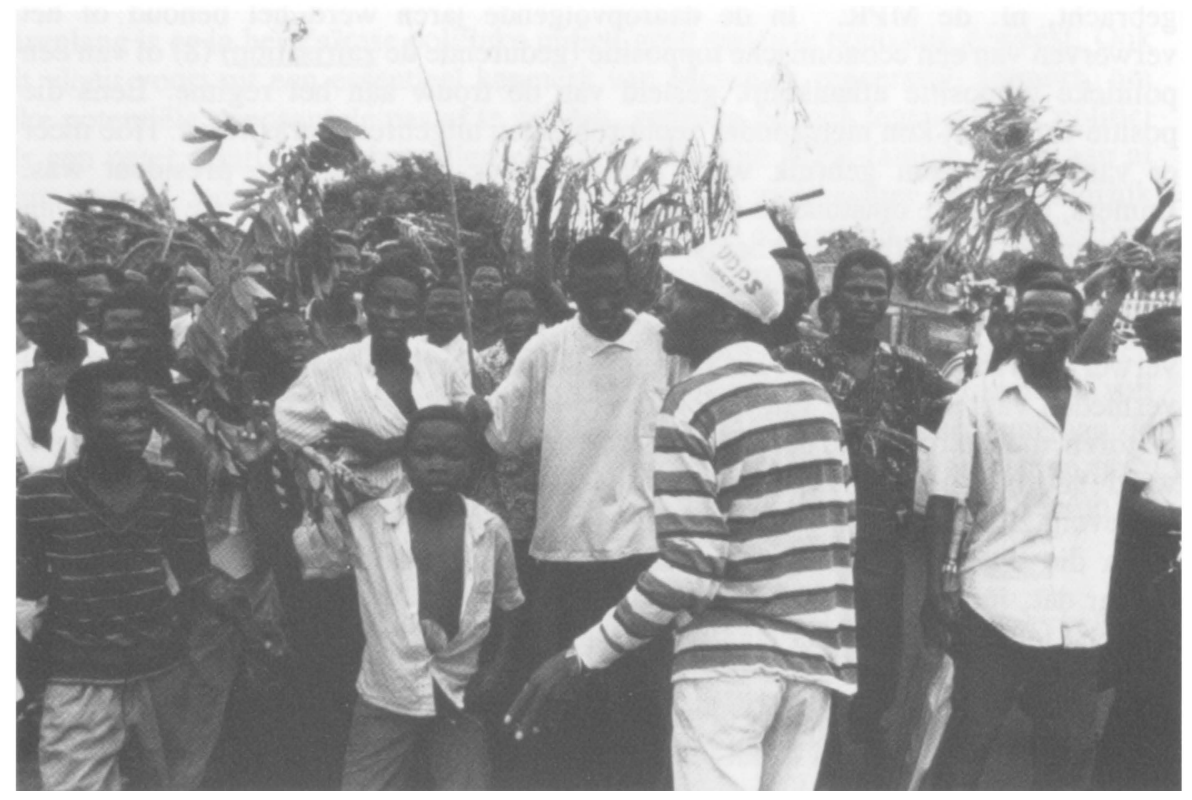

UDPS-betogers in de straten van Kinshasa

Archief Het Volk 


\section{De pandemische corruptie}

Net zoals vele landen die op de overgang staan tussen verschillende economische systemen, heeft Zaïre af te rekenen met corruptie. In Zaïre is de corruptie echter zodanig groot dat het een onderdeel geworden is van het dagelijks leven, zonder hetwelk overleven quasi onmogelijk geworden is (11). Zoals hierboven reeds vermeld, werd in ruil voor een verregaande centralisatie en loyaliteit van de onderdanen, aan deze laatsten de vrije hand gegeven in het beheer van de staat. De economische rationaliteit werd dus opgeofferd aan de machtscontinuïteit.

Binnen het patrimonialistisch concept past dit dan ook uitstekend. Het beheer van de openbare financiën als persoonlijk bezit laat Mobutu immers toe zijn hovelingen loyaal en afhankelijk te houden door de relatie via corruptie van de nodige zuurstof te voorzien. Dit voorbeeld zal aanstekelijk werken en door de ambtenaren nagevolgd worden om hun invloed te vergroten, hun cliënteel uit te breiden, diensten te kopen en verkopen, rijk te worden en hun positie te consolideren (12). We hebben ook gezien dat én van de betrachtingen van het regime was elke uiting van ondernemingsgeest te verstikken door de vorming te vermijden van autonoom kapitaal. Non-produktiviteit en profitariaat vloeien hieruit voort en geven op hun beurt aanleiding tot corruptie.

Zoals we zullen uiteenzetten in punt 7 is ook onzekerheid een belangrijke factor in het leven van alledag, die voortvloeit uit de aard van het regime. Die onzekerheid bestaat erin dat niemand kan rekenen op een vaste positie en op een vast inkomen. Voor hen die op een lucratieve post zitten kan elke dag de laatste zijn, waardoor zij bijgevolg sterk geneigd zijn om hun persoonlijke belangen te dienen (13). Daarbij kent de ambtenarij een systeem van rotatie (als controlemiddel van de overheid) waarbij ambtenaren om de haverklap overgeplaatst worden naar andere streken. Dit geeft nogmaals aanleiding tot onzekerheid. Voor de onmogelijkheid om een samenhangend lange termijn-beleid te formuleren en om zich aan te passen aan een streek vormt de corruptie een lucratief korte termijn-alternatief (14).

Het gevolg van dit alles is dat door de totale afwezigheid van controle de corruptie zich als een olievlek heeft uitgebreid tot alle facetten van het dagelijks leven, of zoals de président-fondateur het zelf gezegd heeft: "En un mot, tout est a vendre. tout peut être acheté dans notre pays." (15).

Het spreekt vanzelf dat met een dergelijke ontwikkeling, waarbij de staat gedegradeerd werd tot de som van de privé-belangen, men moeilijk kan verwachten dat iedereen zich plots bewust is van de noodzaak van burgerzin en van het dienen van het algemeen belang. Het zal voor de overheid in de toekomst zeer moeilijk 
zijn om zich te ontdoen van haar reputatie als forum van profiteurs en om zich, tegen vele van haar bestuurders in, te kwijten van haar echte taak als overheid.

Bovendien heeft de ongebreidelde corruptie er eveneens voor gezorgd dat de economie én grote puinhoop is: de infrastructuur is er praktisch onbestaande, wat reizen en handel drijven in Zaïre tot een heroïsche daad maakt (zie onder meer de reputatie van Air peut-être / Air Zaïre en l'office des trous); de gezondheidszorg staat op een ontzettend laag peil en is er enkel nog voor de meestbiedende. $\mathrm{Er}$ is ook een gigantische parallelle economie ontstaan: minder dan $1 / 3$ van de bevolking neemt nog deel aan de formele economie (16).

Besluitend kunnen we stellen dat wie morgen Zaire zal besturen niet alleen zowat alle voorzieningen van de overheid vanaf de grond zal moeten heropbouwen, maar hiervoor ook zal moeten steunen op een bevolking die van kindsbeen af in een sfeer van corruptie heeft geleefd en er noodgedwongen zelf heeft moeten aan meedoen.

\section{De verhouding met het buitenland}

Net zoals zoveel andere derde wereldlanden zit Zaïre in een periferie-situatie ten opzichte van de geïndustrialiseerde wereld. Wat Zaïre betreft, werd deze positie nog eens extra verzwaard door de aard van het regime. Om de cliëntelistische relaties te onderhouden is er immers een immense massa geld nodig. Dit werd opgelost via een politiek van leenwoede bij Westerse landen, die in ruil voor hun leningen van de uitstekende geopolitieke positie van Zaïre konden profiteren (17).

Daarnaast was het ook voor de bedrijven zeer voordelig zakendoen in Zaïre, tenminste na het fiasco van het economisch nationalisme. Het land werd zowat uitverkocht en heel wat groepen (de Generale, OTRAG, Nippon mining, De Beers, ...) konden naar believen voordeel doen met de grote natuurlijke rijkdommen van het land. Bovendien was er ook een constante geldstroom aan de gang, vanuit Zaïre richting geheime bankrekeningen in het Westen en richting toeleveringsbedrijven van mammoetprojecten.

Zo zien we dat Zaïre in de loop van de jaren een enorme financiële put gegraven heeft waaruit het nog moeilijk zal kunnen opklimmen, want de leningen, die tezamen een gigantische schuld vormen, werden in geen enkel opzicht omgezet in perspectieven op ontwikkeling, waardoor er voldoende opbrengsten zouden komen, ter afbraak van de schuldenberg (18). Nu zit het land echter opgescheept met een 
enorme schuld en met een economie die nog gedurende lange tijd niet-produktief zal zijn.

\section{Het klimaat van onzekerheid}

Zoals reeds aangegeven in punt 4 , was de sfeer van onzekerheid jarenlang een essentieel kenmerk van het regime (19). Deze politieke en economische instabiliteit genereerde op haar beurt een hele reeks factoren die in een interdependente relatie staan en elk nog meer bijdragen tot de onzekerheid.

* De machthebbers zullen hun (kwetsbare en vluchtige) politieke macht zoveel mogelijk pogen om te zetten in tastbare economische macht (via corruptie).

* De centralisatie, die ervoor zorgt dat alle essentiële beslissingen door én man op én plaats genomen worden (door het gebrek aan vertrouwen door onzekerheid) draagt hier ook toe bij. Immers, leger, veiligheidsdiensten en ambtenaren in verafgelegen streken kunnen met een dergelijke slechte infrastructuur onmogelijk afdoende gecontroleerd worden, waardoor de verantwoordelijken in die streken hun eigen bewind gaan voeren.

* Doordat de leiding in Kinshasa niet weet wat er aan de hand is, voelen ze zich bedreigd in hun dominantie en is ook in de beleidscentra zenuwachtigheid en onzekerheid troef. Bovendien staat een dergelijk gebrek aan informatie, zoals er in Zaïre heerst, het uitwerken van een coherent beleid in de weg.

* Gealarmeerd door de overweldigende onzekerheid, zal het regime een ganse constellatie van veiligheidsdiensten uitbouwen die informatie moeten verzamelen om de bevolking kalm te houden. Dit laatste gebeurt dan uitsluitend door burgers vrees aan te jagen en in hen onzekerheid te doen leven.

Door de aandacht te vestigen op de dialectiek van de repressie, ontdekken we de wisselwerking tussen de verschillende instrumenten van de staat aan de ene kant en het groeiend gevoel van onzekerheid bij de burgers aan de andere kant. Voor dit mechanisme bestaan twee oplossingen. Ten eerste kan de staat zijn eigen onzekerheid verminderen door die van zijn onderdanen te vergroten, nl. via de uitbouw van een repressief apparaat. Ten tweede kan men ook zoeken naar middelen om de onzekerheid van de bevolking te verminderen door betere controle op de instellingen van het land en een betere garantie van de grondrechten. Helaas heeft het Mobutu-regime voor de eerste oplossing gekozen en was er dan ook een 


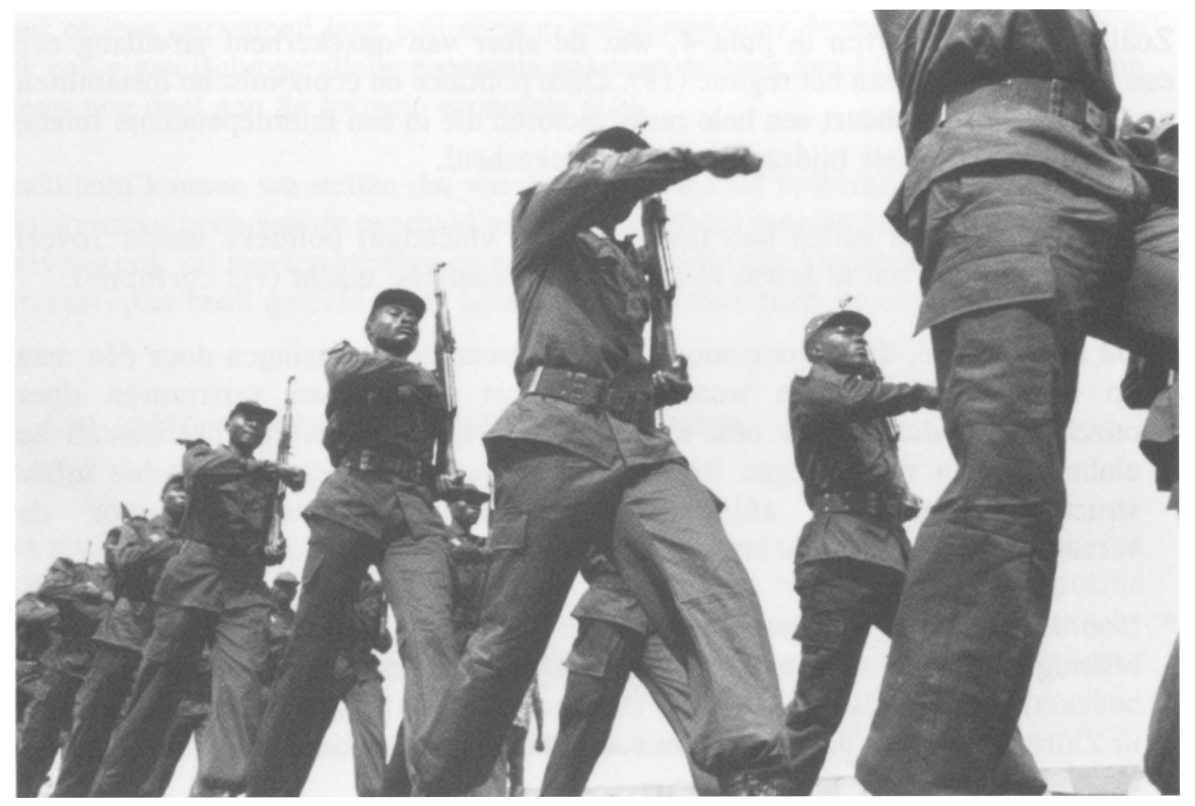

Bij gebrek aan elke bestaanszekerheid en aan middelen heeft het Zairese leger zijn toevlucht gezocht niet alleen tot corruptie maar ook tot regelrecht geweld, wat de chaos alleen maar vergroot. Het leger zal bijgevolg een belangrijke maar labiele factor zijn, waarmee terdege rekening zal moeten gehouden worden

Archief Het Volk ${ }^{\circ}$ 
continue strijd voor ruimte om zich te kunnen ontplooien en zich de nodige zekerheid te verschaffen.

In het kader van wat we vooraf besproken hebben, dienen we dan ook de muiterijen van de strijdkrachten te zien. Bij gebrek aan elke bestaanszekerheid en aan middelen om aan de meest fundamentele behoeften te voldoen, heeft het leger zijn toevlucht gezocht niet alleen tot corruptie, maar ook tot regelrecht geweld, wat de chaos alleen maar vergroot. Het leger zal bijgevolg een belangrijke, maar labiele factor zijn, waarmee terdege rekening zal moeten gehouden worden.

In de toekomst zal dit klimaat van fundamenteel wantrouwen en noodzakelijk egoïsme, dat gedurende decennia gegenereerd en gekoesterd werd door het Mobutistisch regime, en dat ongetwijfeld alle interacties uit het leven van elke Zairees sterk geconditioneerd heeft, zeker niet bijdragen tot een geest van samenwerking die nodig is om het land te doen herrijzen uit de afgrond van de tweede republiek.

De relatief pessimistische vooruitzichten die hierboven naar voor werden geschoven mogen ons echter niet verhinderen ons vertrouwen uit te spreken in het Zaïrese volk. Overal in Zaïre, van de basis tot aan de top van het grootste deel van de politieke en maatschappelijke groeperingen, lijkt er een consensus te heersen: er moet komaf gemaakt worden met de wantoestanden uit het verleden en het regime dat hiervoor verantwoordelijk was. Bovendien lijkt de ondernemersgeest zich weer te doen gelden in het parallel economisch circuit en heeft de bevolking, onafhankelijk van de staat en zijn vangarmen, eigen, weliswaar bescheiden, systemen opgezet om in hun basisbehoeften te voldoen en zich te beschermen tegen de overheid (20). Deze wil tot overleven zal echter zwaar op de proef worden gesteld in de toekomst. We hopen dan ook dat een stevige basis van vertrouwen, eenheid en algemeen belang wordt gevestigd, waarvan op lange termijn iedereen beter zal worden.

\section{NOTEN}

1. Bwana N'Sefu, Les révisions constitutionnelles au Zaïre, Genève-Afrique, $1989, n^{\circ} 2$, p.46.

2. Buana Kabue, Citoyen président, L'Harmattan, Paris, 1978, p. 79.

3. Willame, J.C., Politics and Power in Congo-Kinshasa, Africa Report, 1971, Jan., p. 14.

4. Voor een verdere studie van de patrimonialistische regeerstijl in Zaire, zie ook: Willame, J.C., Patrimonialism and Political Change in the Congo, Stanford University Press, 
Stanford, 1972, en Callaghy, T., The State-Society Struggle, Colombia University Press, New York, 1984.

5. Willame, J.C., 0.c. (1972), pp. 8-33.

6. Doom, R., Machtsverwerving en machtsuitoefening in Kongo-Zaïre, Afrika Focus, vol.2, nr. 3-4, 1986, p. 333.

7. Fungula Fumu Ngondji, Une réflexion sur l'opposition politique, in: Jewsewiecki, B., Etat indépendant du Congo, Congo belge, République démocratique du Congo, République du Zaïre, SAFI press, Québec, 1984, p. 120.

8. Een studie van het gebruik van de zairisation om de elite te verenigen, vinden we terug in: Schatzberg, M., Politics and Class in Zaire, Africana, London/NY, 1980.

9. Callaghy, T., External Actors and the Relative Autonomy of the Political Aristocracy in Zaire, Joumal of Commonwealth and Comparative Politics, 1983, Nov., p. 69-70.

10. Schatzberg, M., Ethnicity and Class at the Local Level Comparative Politics, 1981, 13 (4), p. 473.

11. Voor een beschrijving van het alomtegenwoordig karakter van de corruptie, zie GOULD, D., Bureaucratie Corruption and Underdevelopment, Pergamon, New York, 1980.

12. Gould, D., 0.c., p. 28.

13. Schatzberg, M., Ethnicity and Class at the Local Level, Comparative Politics, 1981, 13 (4), p. 473; Callaghy, T., o.c. (1984), p. 189.

14. Ibid., p. 38.

15. Péan, P., L'argent noir, Fayard, 1978, p.150.

16. Scott Bobb, F., Historical Dictionnary of Zaire, Scarecrow, London, 1988, p.74 Gould, D., 0.c., p. 124-149 .

17. Zie ook Van der Steen, D., Le Zaïre malade de sa dépendance extérieure, Genève-Afrique, 1979, p. 121.

18. Callaghy zoekt in zijn artikel "External Actors and the Relative Autonomy of Political Aristocracy in Zaire", een opmerkelijke verklaring voor de non-produktiviteit van de Zairrese economie: door zich niet in te passen in het kapitalistisch produktiestramien, maar in een overlevingseconomie, wordt men tegelijk ook minder afhankelijk van de geindustrialiseerde landen, die meestal de wetten dicteren in het kapitalistisch systeem. Wanneer Zaire in de toekomst echter zijn schuldenberg zal willen delgen, zal het hiervoor waarschijnlijk kapitalistische produktiemethodes moeten gebruiken, waardoor het in een gewone periferiepositie zal terechtkomen. 
19. Voor een uitgebreide beschrijving van de spiraal onzekerheid - geweld, zie: Schatzberg, M., The Dialectics of Oppression in Zaire, Indiana University Press, Bloomington, 1988.

20. Zie o.a. ook MacGaffey, J., On se débrouille , onuitgegeven paper; Devos, J. \& Vandommele, M., Overleven is een kunst, De wereld morgen, 1985, nr. 2, p. 7-8 en Basisgroepen, maar nog zeer geïsoleerd, De wereld morgen, 1985, nr. 3, p. 13-14. 